hand, flying is more popular than ever before. British passenger numbers are predicted to double to 475 million per year by 2030 , for example, and in China, according to the World Bank, passenger numbers grew by a whopping 28\% from 2003 to 2004 .

Progress in improving the fuel efficiency of aircraft is, by contrast, gradual. Current trends suggest that gains of $1-2 \%$ per year will be the norm for the foreseeable future. Only a step change in aeroengine design might increase this, but with current approaches being so safe and reliable, and change so expensive, that seems improbable.

As a result, the growth in aviation emissions, if left unchecked, is liable to wreck attempts to reduce greenhouse-gas emissions. In Britain, for example, airlines' emissions are growing by around 7\% each year, even as the government prepares to set in law a commitment to cut national emissions to 60\% below 1990 levels by 2050 . According to the Tyndall Centre for Climate Change Research, the rest of the economy would have to move to zero emissions in order to sustain aviation growth and meet the target.

It is clear that something will have to give. If real cuts are to be made in carbon emissions, aviation growth will certainly have to level off. The number of trips may even need to be cut. These are truths that the airline industry does not want to hear.

The first moves towards such a future are now being made. The European Commission announced in December that it plans to include domestic flights in its carbon emissions trading scheme by 2011, with intercontinental flights joining the scheme the following year. This is a critical first step towards a future in which consumers start to pay for the environmental cost of flying.

For now, several European airlines say they are in favour of emissions trading, perhaps because they anticipate being eased gently into the scheme with relatively generous emissions targets. The full test of their support will come in the years after the scheme starts, when emissions will need to be capped tightly enough to reduce the growth in airline traffic.

But some, led by O'Leary's Ryanair, are opposed from the start. US airlines are sending an equally indignant message behind the scenes, Pearson says. This opposition may lead to a legal challenge from US airlines to the proposed inclusion of intercontinental flights.

European Commission officials say they are confident of the legality of their approach. But if the US legal action or non-cooperation of the airlines make emissions trading unworkable, more radical alternatives may have to be considered. One such approach would be to review European adherence to the 1947 Chicago Convention, the international agreement that prohibits the taxation of aviation fuel, and hence gives the industry a permanent advantage over its competition, such as rail travel. That would really give O'Leary and his allies something to squeal about.

\section{Competitive stumbling}

\section{Promised investment in the physical sciences is held up in a US budget jam.}

$\mathrm{n}$ his State of the Union Address last January, President George W. Bush announced an American Competitiveness Initiative, which included substantial increases in funding for the physical sciences as a means of securing US industrial competitiveness in the long term. This laudable initiative set out to increase expenditure on research in physics, engineering and other disciplines at the National Science Foundation, the Department of Energy and the National Institute of Standards and Technology.

Leading Republicans and Democrats have expressed strong support for such a step, and as the president's proposal moved through the congressional budget process last year, all three agencies were looking forward to significant growth during 2007.

But despite the goodwill, an unusual turn in the budget saga has caused the gains to vanish overnight. The outgoing Republican Congress never finished the 2007 budget, as it should have done by 1 October 2006. That left the incoming, Democrat-controlled one to decide what to do with the unfinished appropriations bills. But the Democrats want to focus on the issues that they think got them elected, such as lobbying reform and the war in Iraq. Instead of completing last year's spending bills, the Democrat chairs of the appropriations committees have said they plan to stick with 2006 funding levels through the whole of the 2007 fiscal year (see page 130).

The announcements left lab directors and agency administrators who stood to benefit from the competitiveness initiative protesting about sharp cutbacks in extramural grants and sidelined intramural facilities. Some of this is exaggerated, but there is no denying that the physical sciences will suffer as a result of this turn of events. Because the House and Senate had already approved the increases, agencies were incorporating them into budget planning. Tough choices must now be made at the last minute to ensure that the agencies can operate until 30 September, when the fiscal year ends. In other words, the sudden retraction of the increases is more damaging than if they had never been mooted in the first place.

The bill to keep spending at 2006 levels will probably be finalized and passed in the next few weeks, and science lobbyists in Washington are scrambling to have an exception made for the competitiveness initiative. They have a strong case, and given the bipartisan support for the initiative's main elements, they deserve to succeed. Unfortunately, it is more likely that appropriators will make exceptions only for a few politically sensitive agencies, such as the Department of Veterans' Affairs.

All eyes will then turn to the presi-
"The sudden retraction of the funding increases is more damaging than if they had never been mooted in the first place." dent's budget proposal for 2008, to be released on 5 February. Despite the president's well-known political difficulties, his proposal will set the tone for the subsequent budget process. Science advocates have been pressing hard to ensure that Bush's proposal makes up for this year's shortfalls. And scientists should urge their own congressional representatives to ensure that the 2008 budget reflects both the withdrawn increase for 2007 and that originally envisaged for 2008. With the right support, it may still be possible to get the American Competitiveness Initiative back on track. 